\title{
Gonad maturation and spawning of cobia, Rachycentron canadum (Linnaeus, 1766) off the Dungun coast, Malaysia
}

\begin{abstract}
The reproductive biology of cobia, Rachycentron canadum, from the coastal waters of Dungun, Malaysia was studied from June 2014 to May 2015. From commercial trawls, a total of 201 samples (combined sexes) were collected (fork lengths [FL] $37.5-124.0 \mathrm{~cm}$; body weights $0.5-20.4 \mathrm{~g}$ ). The overall sex ratio of females to males was 1:0.9, which was not significantly different $\left(\chi^{2}=2.12\right.$, df $\left.=1 ; \mathrm{p}<.05\right)$. Estimations of length at $50 \%$ maturity (L50) showed that both sexes matured at approximately $75 \mathrm{~cm}$ FL; estimated spawning frequency was 6 days. Mean batch fecundity (BF) ranged from 0.55 to 4.32 million eggs. The average number of eggs per gram of ovary was from 2,100 to 5,400 eggs, and relative fecundity 147 eggs/g. There was a weak positive correlation $(\mathrm{r} 2=.48)$ between BF and female FL as well as $\mathrm{BF}$ with an ovary-free body weight $(\mathrm{r} 2=.56)$, possibly due to females being in a continuous spawning condition and some possibly half-spent, based on the histological examination of the female gonads. Despite cobia being asynchronous spawners, the gonadosomatic index in both males and females showed peaks in June, November, and particularly March. Based on histological examination, spawningcapable males were encountered throughout the study period, whereas spawningcapable females in the late developing subphase were found mostly in March and April. This is the first study on the reproductive aspects of cobia in Malaysian waters.
\end{abstract}

Keyword: Gonad maturation; Cobia, Rachycentron canadum; Dungun coast; Malaysia 
